\title{
Use of close-range photogrammetry and UAV in documentation of architecture monuments
}

\author{
Gabriela Wojciechowska ${ }^{1, *}$ and Jakub Luczak $^{1}$ \\ ${ }^{1}$ Wroclaw University of Science and Technology, Faculty of Geoengineering, Mining and Geology, 27 Wyb. Wyspiańskiego St., \\ 50-370 Wroclaw, Poland
}

\begin{abstract}
The available photogrammetric solutions, combined with properly conducted surveying measurements enable to create fully applicable, three-dimensional models of architectural structures, which can be applied in, i.e. protection of cultural heritage or conservational documentation. Currently, we can see an increase in use of digital non-metric cameras in a photogrammetric inventory of sacred monuments. Properly obtained and analysed data allow to create a digital model of an object, which later might serve as a basis for a vector image used for architectural and construction purposes. The paper presents the procedure of creation of 3D models of sacred historic monuments of relatively small sizes with the use of terrestrial photogrammetry and UAV using the Agisoft PhotoScan Professional software.
\end{abstract}

\section{Introduction}

Currently applied procedures aiming at the creation of models of physical structures, including threedimensional models of architectural structures, take advantage of modern technologies, such as: high-tech total stations, increasingly more efficient laser scanners, as well as photogrammetric software used for automatic processing of image data. In recent years there has been an increase in use of non-metric cameras in a photogrammetric inventory of monuments. The development of technology and its increasing accessibility led to popularization and wide use of those high-tech solutions [1-3].

Agisoft PhotoScan, Autodesk ReCap and numerous other kinds of software (including open source) enable obtaining models of structures basing merely on digital two-dimensional images. Moreover, due to the availability of such software on mobile devices, the technology becomes accessible within reach. Just like the transition from analogue to digital photography enabled photographing of almost everything at any given moment, the development of software basing on photogrammetry makes it possible to possess a selfmade digital model on one's mobile phone.

The above technologies provide significant support for such professions like architects, conservators or archaeologists.

The aim of the paper is to present the possibilities connected with preparing documentation of architectural monuments with the use of Unmanned Aerial Vehicles (UAV) and methods of terrestrial photogrammetry. The article elaborates on the course of action of the creation of $3 \mathrm{D}$ models of sacred landmarks of relatively small sizes with the use of terrestrial photogrammetry and UAV as well as the assessment of their utility in the inventory of landmarked buildings.

\section{Materials and methods}

The accurateness of architectural structure model created with the use of photogrammetric methods depends primarily on: image registration, camera parameters and its proper calibration and rectification, achieved overlay of consecutive images in blocks, a shape of metering network or the number of checkpoints [4].

Currently used software bases mainly on automatic image matching algorithms, which serve as a highly effective tool for processing entire blocks of both metric and non-metric digital images [5]. Agisoft PhotoScan software, which was applied in the paper, basis on methods of automatic image matching. The programme uses algorithms based on the SIFT (Scale-Invariant Feature Transform) algorithm, which analyses and compares the parameters pixel by pixel in order to determine local features in an image, generating socalled image descriptors. Such descriptors are next used for detection of identical points in images which comprise a common block (all defined in the project, not only between two proximal ones which constitute a stereo pair) [6].

The application of a model created with the use of photogrammetric methods for purposes connected with monument documentation is usually connected with the necessity for obtaining the representation of the entire body of a structure and assigning metrics to it. The article presents the application of models of two architectural structures in drawing up architectural

\footnotetext{
* Corresponding author: gabriela.wojciechowska@pwr.edu.pl
} 
documentation. Both models (St. Martin Church, Wrocław and Parish Church in Pożarzysko, Żarów District) were made with the use of Agisoft PhotoScan Professional software. The procedure of building an architectural structure model in the aforementioned environment is presented in Table 1. Models created for the purpose of the study were created with the use of two methods using different sources of image data, nevertheless, the applied procedure remained the same. The usability of both methods in the process of obtaining data for architectural documentation was analysed. During the process of analysis, the primary focus was data concerning the exterior of both structures; models of interiors were not created.

Table 1. Stages of creation of 3D model using Agisoft PhotoScan Professional software.

\begin{tabular}{|c|c|}
\hline Obtaining of data & $\begin{array}{c}\text { Obtaining of } \\
\text { photogrammetric data and } \\
\text { (optional) structure } \\
\text { surveys. }\end{array}$ \\
\hline image masking & $\begin{array}{l}\text { Image masking: overlaying } \\
\text { of (1-bit) bicolour image on } \\
\text { the picture in order to mark } \\
\text { areas which are to be } \\
\text { omitted - in order to } \\
\text { optimize modelling } \\
\text { process. }\end{array}$ \\
\hline Import of control points & $\begin{array}{l}\text { Import of control points, } \\
\text { preferably in defined } \\
\text { geodetic coordinate system } \\
\text { - in order to accurately } \\
\text { reconstruct spatial } \\
\text { relationships. }\end{array}$ \\
\hline Bundle-adjustment & $\begin{array}{c}\text { Assignation of basic } \\
\text { calibration parameters and } \\
\text { their automatic distribution } \\
\text { - the outcome: sparse point } \\
\text { cloud (tie points) and } \\
\text { collection of camera } \\
\text { positions (exterior } \\
\text { orientation). }\end{array}$ \\
\hline $\begin{array}{l}\text { Generation of dense } \\
\text { point cloud }\end{array}$ & $\begin{array}{l}\text { Generation of dense point } \\
\text { cloud basing on the } \\
\text { collection of camera } \\
\text { positions and images. }\end{array}$ \\
\hline $\begin{array}{l}\text { Reconstruction of a 3D } \\
\text { model }\end{array}$ & $\begin{array}{l}\text { Generation of } 3 \mathrm{D} \text { polygon } \\
\text { mesh representing the } \\
\text { structure surface basing on } \\
\text { dense point cloud. }\end{array}$ \\
\hline Model texturing & $\begin{array}{c}\text { Texturing and/or } \\
\text { generating of orthophoto } \\
\text { elevation basing on } \\
\text { reconstructed geometry } \\
\text { (mesh). }\end{array}$ \\
\hline $\begin{array}{l}\text { Recording in external } \\
\text { formats }\end{array}$ & $\begin{array}{l}\text { Export of a model and/or } \\
\text { point cloud in commonly } \\
\text { applied external formats. }\end{array}$ \\
\hline
\end{tabular}

\subsection{Integration of close-range photogrammetry, UAV and surveying measurements (St. Martin Church, Wrocław)}

St. Martin Church, Wrocław is a small gothic church located in the western part of Ostrów Tumski (Cathedral Island), dated back to the end of $13^{\text {th }}$ century. The church was a two-storey structure, currently, due to the elevation of the surrounding ground by several meters, the lower level is located below the ground and has a character of a crypt.

Two sources of data were applied for creating the model of St. Martin Church: close-range terrestrial photogrammetry and photographs taken by the means of photogrammetric low-altitude flight. In order to obtain the metricity of a model surveying measurements of control points of building's façade were taken basing on geodetic measurement network using the combined method. This method consists of a determination of approximate coordinates using GNSS method and their alignment with the use of angular and linear network and trigonometric levelling. Survey data were obtained with the use of total station in reflectorless mode, after a prior positioning above the control point. As a result, 54 control points evenly covering the shape of the building were established.

During conducting the measurement two low-altitude photogrammetric flights were conducted; the first in order to obtain almost vertical photographs aiming at creating the imagery of the roof of church and other places impossible to portray by terrestrial images, and the second one with a camera angled at $30^{\circ}$ aiming at capturing angled images representing the highest parts of the wall which contact the roof. Terrestrial imagery was arranged on the same day, which enabled obtaining images with the use of both methods with similar parameters, taken in identical weather conditions. In addition, it was attempted to photograph at the same time, both from the air and from the ground, control points created for this purpose in the form of $45^{\circ}$ angled metal strips - which enabled a simultaneous alignment of both image blocks.

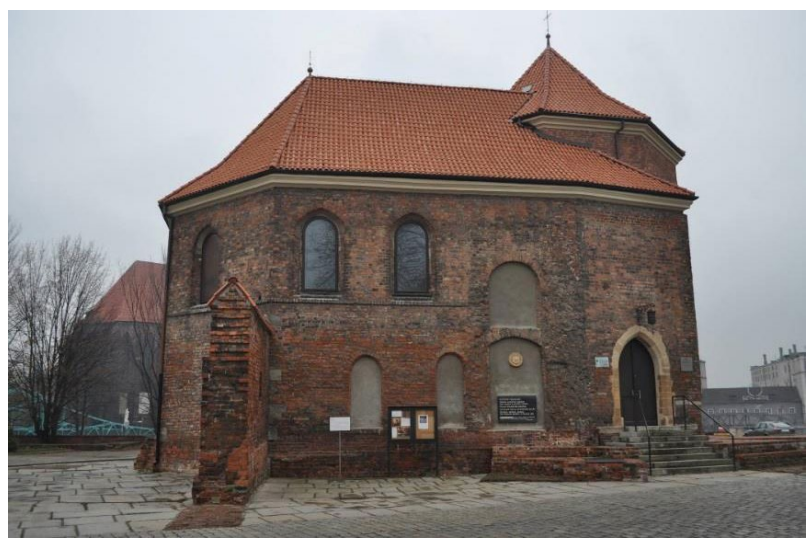

Fig. 1. St. Martin Church in Wrocław.

In total, the study used 98 close-range terrestrial photogrammetry photographs taken with Nikon D800, and 84 aerial low-altitude photogrammetry photographs 
obtained with the use of Canon A810 compact camera; including 54 photographs taken with a camera with the vertical axis and 30 oblique images. As a result, a 69313 tie points were obtained (Fig. 2), which was next used to generate a dense point cloud (17.8 million points), a mesh model (Fig. 3), shaded coloured model (Fig. 4) and textured model (Fig. 5). The dimensions of the model, which was developed in the local coordinate system, was referenced with field measurements taken directly from the object. The accuracy of the model was determined at the level of $2.0 \mathrm{~cm}$ - as mean squared error (MSE) of field measurements of 43 details regularly placed on the object which are to be subject to architectural documentation, i.e. façade elements, stairs, windows.

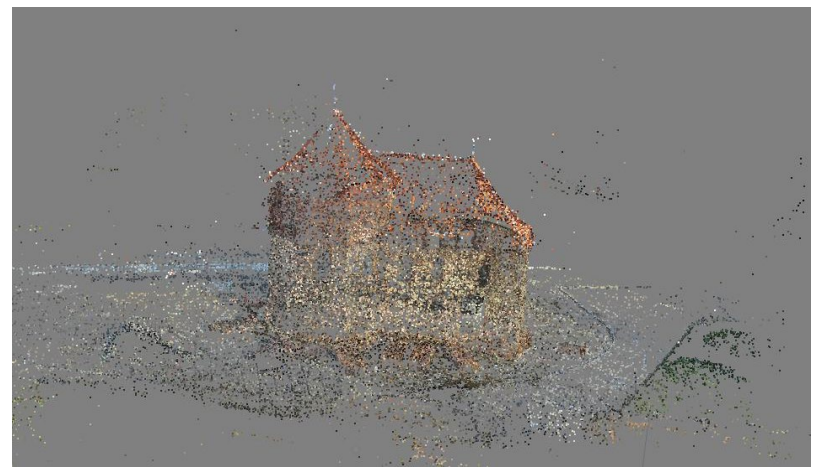

Fig. 2. Distribution of tie points used in bundle adjustment (sparse point cloud) of St. Martin Church in Wrocław model.

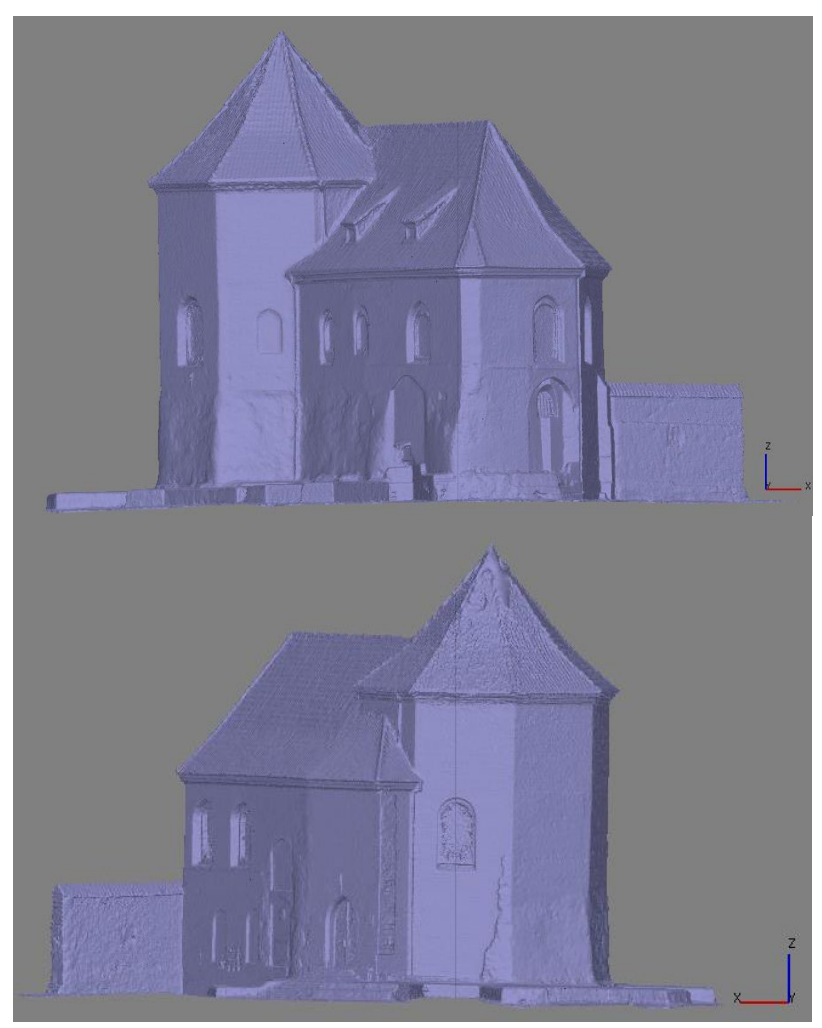

Fig. 3. Mesh models of St. Martin Church in Wrocław model (top - the view from the south side; bottom - view from the north side).

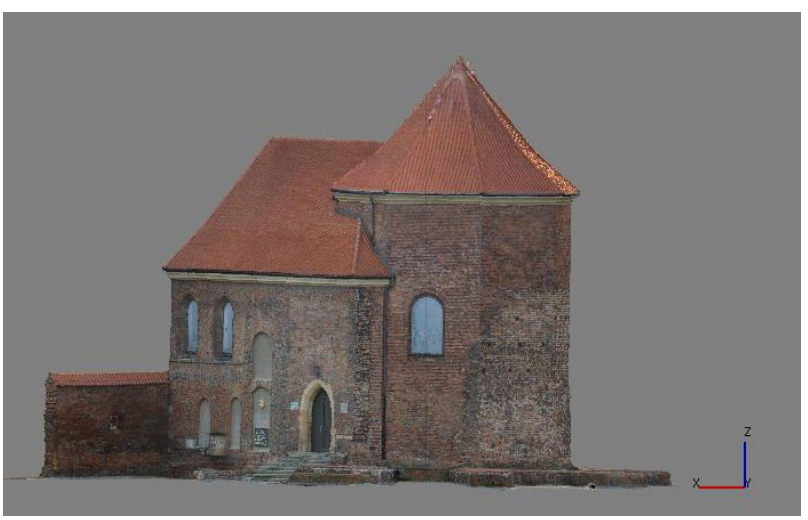

Fig. 4. Shaded coloured model of St. Martin Church in Wrocław model; view from the north side.

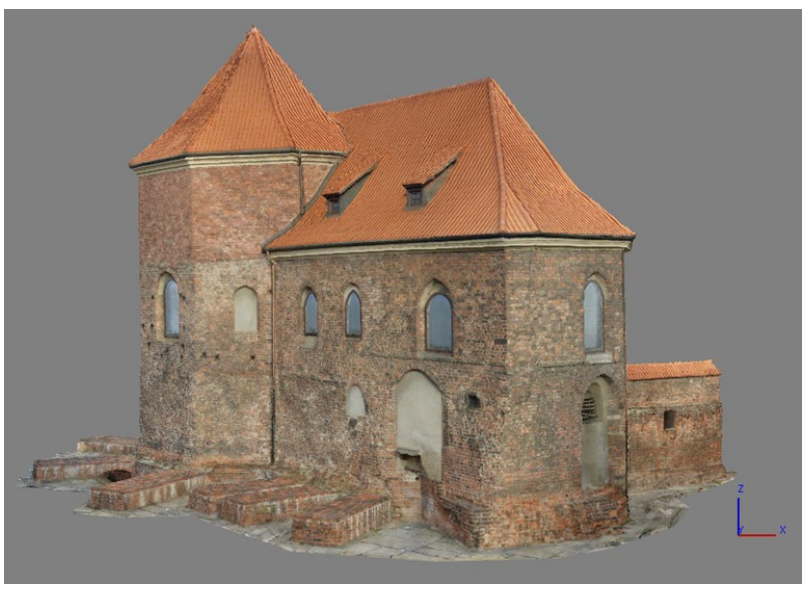

Fig. 5. Textured model of St. Martin Church in Wrocław model; view from the south side.

\subsection{Application of sole UAV imagery (Church in Pożarzysko, Żarów District)}

Parish Church in Pożarzysko (Fig. 6) features an original spatial form which consists of a square vaulted presbytery, elongated rectangular nave covered with a ceiling, with semi-circular chapels on the sides. The presbytery windows, portals and the presbytery vault allow to trace back the time of construction of the structure to the mid- $13^{\text {th }}$ century. The interior dimensions of the church are as follows: presbytery $7.68 \times 6.93 \mathrm{~m}$, nave $17.86 \times 9.26 \mathrm{~m}$ [7]. The church was built of crushed granite and stone joints used in corners and for details. A late Romanesque portal of high artistic value has been preserved in the southern wall.

Due to the post-war neglect, the church fell into ruin, however, it was rebuilt in the 1970s.

In the case of the model of this structure, the authors used only images obtained by low-altitude photogrammetric flight of UAV DJI Phantom 4, equipped with a dedicated camera. The axis of the camera was set perpendicularly to the façade of the building, at an angle of approx. $45^{\circ}$, as well as perpendicularly to the ground. 156 images were used for the alignment. 115531 tie points were obtained, and dense point cloud of 42.8 million points. Similarly to the abovementioned example, mesh, shaded coloured and 
orthoimages textured models were generated (Figs. 7-10).

Due to lack of surveying measurements included in the study, in the course of alignment process the authors based solely on automatically matched tie points. The metricity of the model was assigned using external software (MeshLab), basing on the real dimensions of the structure measured in a field. The accuracy of the model was determined to be on the level of $3.2 \mathrm{~cm}$ (as MSE of field measurements of 34 details regularly placed on the object).

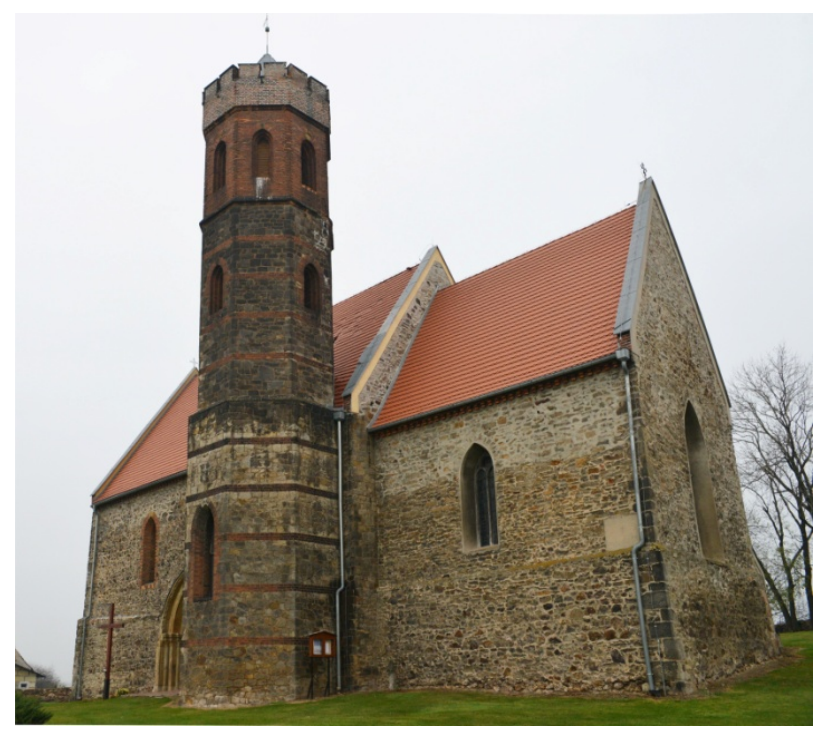

Fig. 6. Church in Pożarzysko.

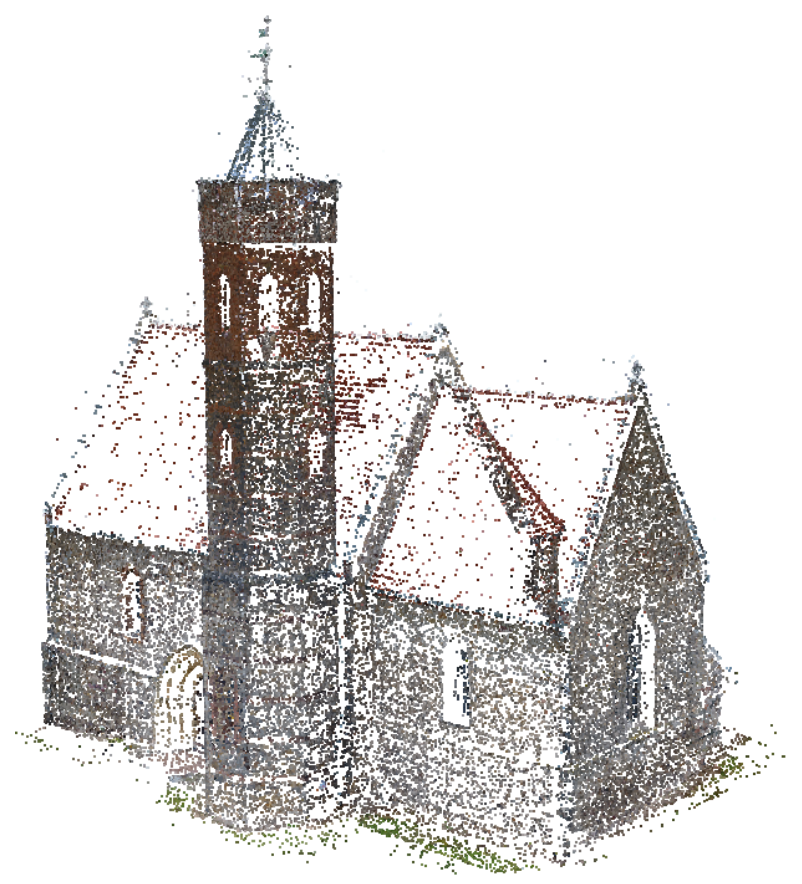

Fig. 7. Distribution of tie points used in bundle adjustment (sparse point cloud) of Church in Pożarzysko.

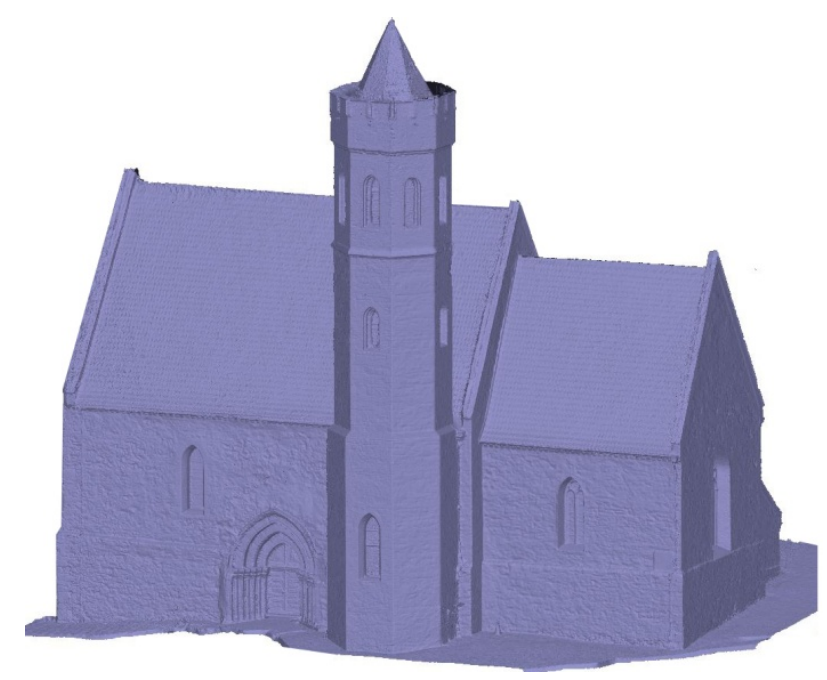

Fig. 8. Mesh model of Church in Pożarzysko.

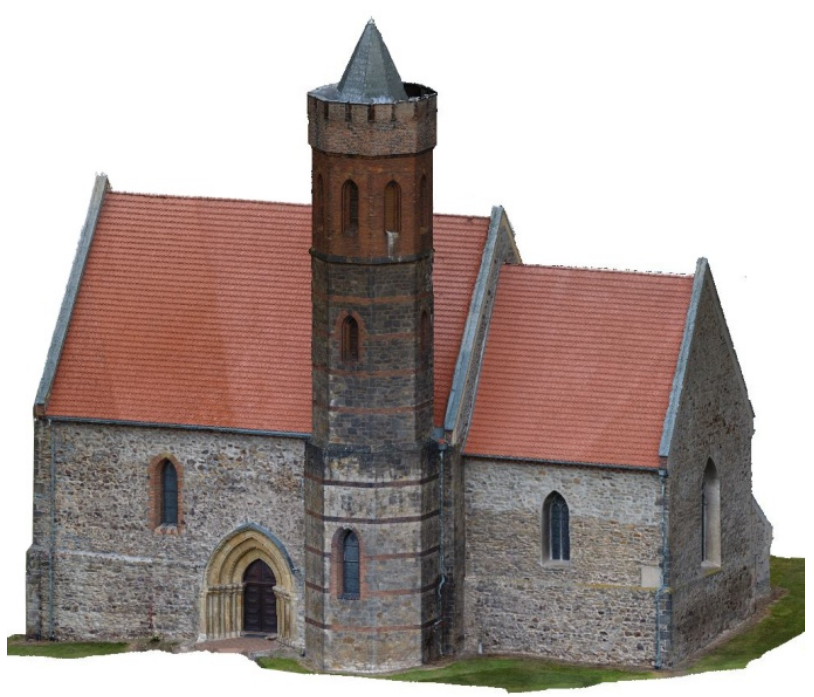

Fig. 9. Shaded coloured model of Church in Pożarzysko.

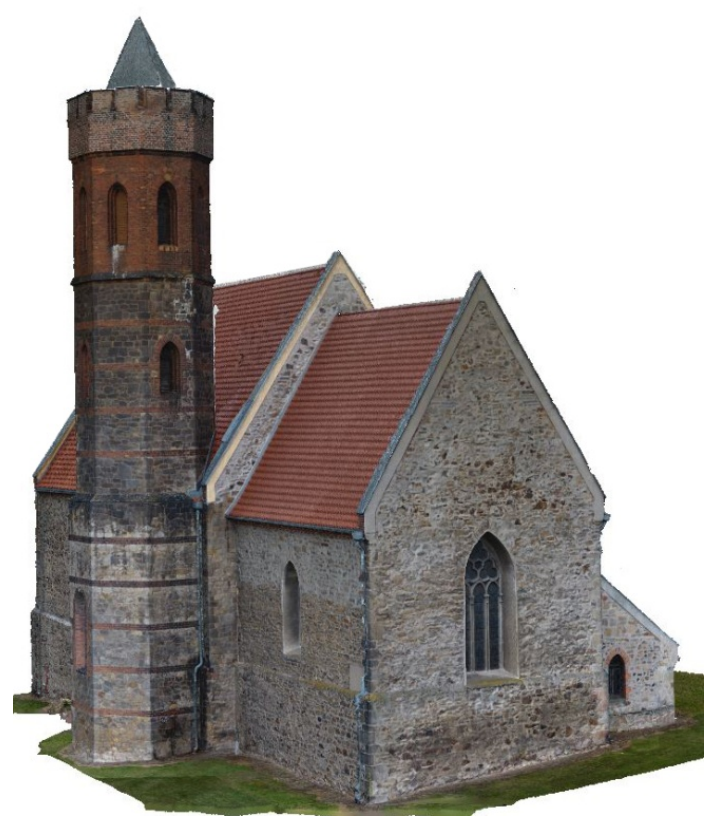

Fig. 10. Textured model of Church in Pożarzysko. 


\section{Drawing inventory of architecture monuments}

Currently, inventorying of monuments using photogrammetric methods or laser scanning is becoming a standard; the process enables digital storing of information concerning not only the dimensions of a structure, but also its colour and texture, and with subsequent studies enables to track changes in the structure in a way easier than ever before.

The basis for the publication of descriptions of architectural studies are images (visualization of results, documenting the structure) [8]. Drawing inventory is, in simple terms, the collection of all plans created according to scale, it usually contains horizontal projections, sections, façades and details. The scope of inventory depends on the type of structure, applicable regulations and requirements specified by the designer, e.g. when inventory is used as a basis for the development of a construction project. The above factors also affect the choice of scale and range of images.

First, it is necessary to determine the required accuracy of the study, i.e. the scale of vector images; next to select a proper method. Lack of use of instruments and methods enabling obtaining accuracies in accordance with existing standard requirements in the inventory process results in the emergence of unnecessary costs and expenses [9].

There are various options concerning the classification and image accuracy of inventorying of architectural monuments. Several studies concerning standardisation of measurements are available in Poland: G-3.4 Inventory of urban complexes, greenery complexes and architectural structures together with the proposal of its amendment [10], proposal of standardization of measurement and drawing inventory of wooden architecture monuments (three-step accuracy scale) [11], as well as German four-step accuracy scale [12].

Typical scales used for development of image documentation (projections, sections, façades) are 1:100, $1: 50,1: 25$ (1:20) or bigger; for the scale 1:100 the assumed accuracy of measurements is $\pm 10 \mathrm{~cm}$, and for the $1: 20$ scale $\pm 2 \mathrm{~cm}$. Higher accuracies are required for instance for statistical calculations and inventory of architectural details (scales of 1:20, 1:10. 1:5, 1:2, 1:1).

Therefore, as it may be observed, developed models due to the obtained accuracies may serve as a basis for creation of image documentation in scales not bigger than 1:25. It is worth noticing that, with the right selection of tools, method and structure (e.g. relatively accessible architectural detail), there is a possibility of obtaining the accuracy of a 3D model obtained basing on photogrammetric imagery of $1 \mathrm{~cm}$ or less, which would enable the use of such model in order to develop documentation with bigger scales (Figs. 11 and 12).

When developing conservational documentation, it is mandatory to document the condition of a monument before attempting any construction work. In case of buildings which undergo the inventory process as part of restoration works and various chronological phases of a structure are revealed and ultimately covered, the photogrammetric documentation with the use of a nonmetric camera is a quick and relatively inexpensive way of documenting the condition of a structure at various stages of work. This also applies to structures that are inventoried during archaeological excavations. The use of UAV systems gains in popularity in archaeological research due to its considerable potential concerning the speed, costs and accuracy [13]. What is more, the system is also applied in case of condemned buildings which cannot be preserved for future generations. Moreover, the software i.e. Agisoft PhotoScan is widely used in modelling of architectural details and single elements of façades [14]. Therefore, virtual models are mappings closest to the original and they provide relevant information for researchers and other interested groups.

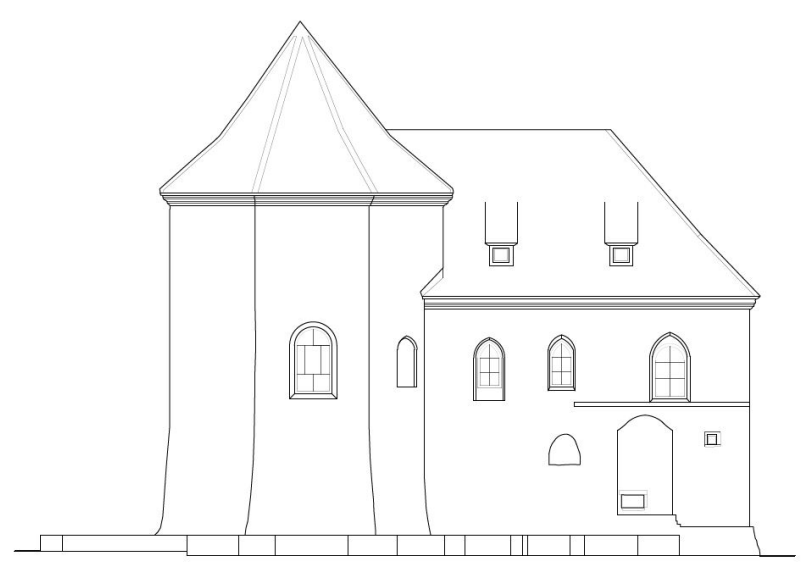

Fig. 11. Architectural-building inventory of St. Martin Church, Wrocław (southern façade).

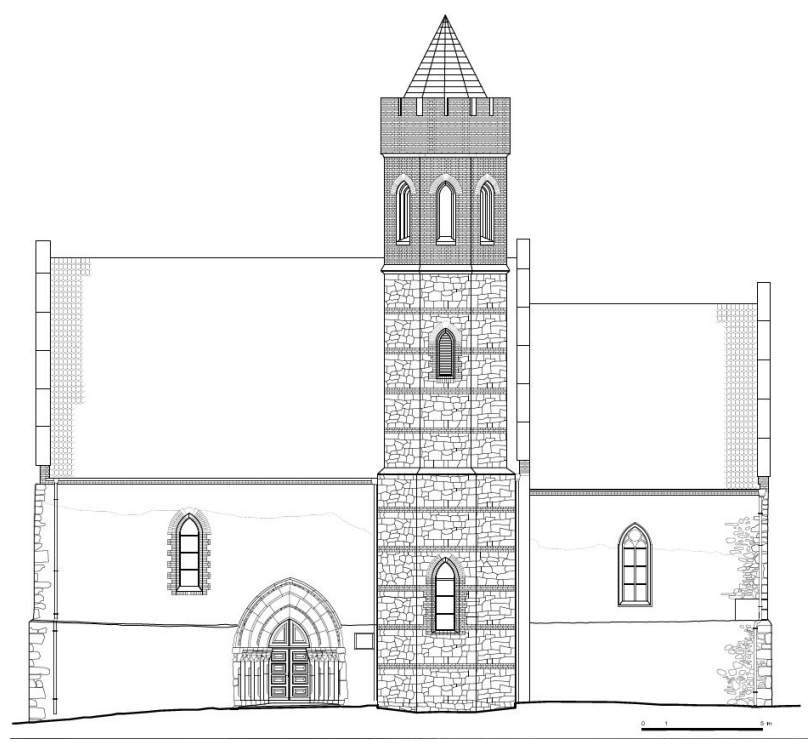

Fig. 12. Architectural-building inventory of Church in Pożarzysko (southern façade).

\section{Summary}

Photogrammetric solutions currently available on the market enable to create fully usable three-dimensional models of architectural structures, which might be used 
for protection of cultural heritage and development of conservation documentation. The described methods are full-value solutions for obtaining information concerning architectural structures, which serve as an alternative especially for laser scanning.

Drawing inventory of architectural monuments can be carried out with the use of traditional methods, however, modern technologies, such as terrestrial photogrammetry and UAV with the use of non-metric camera are of great importance for the documentation of historic buildings. New technologies allow relatively quickly and accurately to develop a 3D model of a monument or its individual elevations, which constitute a good base for creating vector images of a structure. Among the issues concerning the inventory of historic monuments of big sizes there are: analysis of highly located architectural details and measurements of inaccessible elements. Application of UAV enables the access to inaccessible places therefore, in many cases, there is no necessity for using scaffoldings or aerial platforms.

Among possible final effects based on taken photographs which might proof useful in heritage documentation are: point cloud of an analysed structure, mesh model, orthoimage of elevation or digital model of monument's surrounding. Basing on the obtained orthoimages of a façade it is easy to draw brick layering types, walling overs, stone arrangement in a wall, without additional measurements.

The study has demonstrated that it is a material allowing to create vector documentation with the accuracy required to develop documentation in the scale of 1:100,1:50, and even 1:20, although in certain cases it may be necessary to perform supplementary measurements using other methods in order to obtain dimensioning of selected elements with appropriate accuracy.

\section{References}

1. A. Boroń and A. Rzonca. Roczniki Geomatyki, 5, 129-140 (2007)

2. F. Agnello and M. Lo Brutto, ISPRS Archives XXXVI, 5/W47 (2007)

3. J.S. Markiewicz and D. Zawieska, ISPRS Archives XL-5, 395-400 (2014)

4. M. Jaud, S. Passot, R. Le Bivic, C. Delacourt, P. Grandjean, N. Le Dantec, Remote Sensing, 8, 465 (2016)

5. R. Preuss, Archiwum Fotogrametrii, Kartografii i Teledetekcji, 26, 119-127 (2014)

6. Agisoft LLC, Algorithms used in Photoscan, http://www.agisoft.com/forum/index.php?topic=89, Retrieved May 30, 2018

7. T. Kozaczewski, Wiejskie kościoły parafialne XIII wieku na Ślasku (miejscowości P-S) (Wrocław, 1994)

8. A. Drużyński, [In:] Badania architektoniczne. Historia i perspektywy rozwoju (Toruń, 2015)
9. J. Uchański, P. Falkowski, L. Sörensen, Archiwum Fotogrametrii, Kartografii i Teledetekcji, 18, 633641 (2008)

10. P. Falkowski, Z. Parzyński, J. Uchański, Roczniki Geomatyki, 8, 47-62 (2010)

11. M. Prarat and U. Schaaf, Budownictwo i Architektura, 14, 99-110 (2015)

12. G. Eckstein and J. Gromer. Empfehlungen für Bauaufnahmen: Genauigkeitsstufen, Planinhalte, Kalkulationsrahmen, Stuttgart (1986)

13. M.L. Brutto, A. Borruso, A. D'Argenio. International Journal of Heritage in the Digital Era, 1, 7-13 (2012)

14. G. Robleda Prieto and A. Pérez Ramos. Archives of the Photogrammetry, Remote Sensing and Spatial Information Sciences, 40, 263-270 (2015) 